\title{
Time series analysis of fine particulate matter and asthma reliever dispensations in populations affected by forest fires
}

\author{
Catherine T Elliott ${ }^{1,2^{*}}$, Sarah B Henderson ${ }^{1,2}$ and Victoria Wan ${ }^{1}$
}

\begin{abstract}
Background: Several studies have evaluated the association between forest fire smoke and acute exacerbations of respiratory diseases, but few have examined effects on pharmaceutical dispensations. We examine the associations between daily fine particulate matter $\left(\mathrm{PM}_{2.5}\right)$ and pharmaceutical dispensations for salbutamol in forest fire-affected and non-fire-affected populations in British Columbia (BC), Canada.
\end{abstract}

Methods: We estimated $\mathrm{PM}_{2.5}$ exposure for populations in administrative health areas using measurements from central monitors. Remote sensing data on fires were used to classify the populations as fire-affected or non-fireaffected, and to identify extreme fire days. Daily counts of salbutamol dispensations between 2003 and 2010 were extracted from the BC PharmaNet database. We estimated rate ratios (RR) and 95\% confidence intervals (Cls) for each population during all fire seasons and on extreme fire days, adjusted for temperature, humidity, and temporal trends. Overall effects for fire-affected and non-fire-affected populations were estimated via meta-regression.

Results: Fire season $\mathrm{PM}_{2.5}$ was positively associated with salbutamol dispensations in all fire-affected populations, with a meta-regression RR $(95 \% \mathrm{Cl})$ of $1.06(1.04-1.07)$ for a $10 \mathrm{ug} / \mathrm{m}^{3}$ increase. Fire season $\mathrm{PM}_{2.5}$ was not significantly associated with salbutamol dispensations in non-fire-affected populations, with a meta-regression RR of 1.00 (0.98-1.01). On extreme fire days $\mathrm{PM}_{2.5}$ was positively associated with salbutamol dispensations in both population types, with a global meta-regression RR of 1.07 (1.04 - 1.09).

Conclusions: Salbutamol dispensations were clearly associated with fire-related $\mathrm{PM}_{2.5}$. Significant associations were observed in smaller populations (range: 8,000 to 170,000 persons, median: 26,000) than those reported previously, suggesting that salbutamol dispensations may be a valuable outcome for public health surveillance during fire events.

Keywords: Fires, Smoke, Air pollution, Asthma, Pulmonary disease chronic obstructive, Epidemiology

\section{Background}

The public health effects of acute environmental exposures are often described as a pyramid, with the rarest outcomes at the peak and the more common outcomes at the base. The rarest outcomes are most severe, while the most common outcomes are the mildest. Many population-based studies focus on the upper part of the

\footnotetext{
* Correspondence: Catherine.Elliott@bccdc.ca

${ }^{1}$ British Columbia Center for Disease Control, Environmental Health Services, BC Centre for Disease Control, Main Floor, 655 12th Ave W, Vancouver, BC V5Z 4R4, Canada

2University of British Columbia School of Population and Public Health, 2206 East Mall, Vancouver, BC V6T 1Z3, Canada
}

pyramid because severe outcomes are typically recorded in administrative databases. However, their rarity makes it challenging to evaluate short-lived exposures with adequate statistical power, even in large populations. In the case of forest fire smoke, only two [1,2] of five [3-5] studies have reported significant associations between smoke-related particulate matter (PM) and all-cause mortality, and effects specific to respiratory mortality were not clear. Similarly, time-series studies have reported significant associations between smoke-related PM and respiratory hospital admissions in multiple settings [6-10], but most have been conducted in large towns or cities,

\section{Biomed Central}


and not in the remote and rural areas most affected by fire smoke.

The effects of forest fire smoke on milder health outcomes have generally been examined in smaller panel studies [11-14] due to the absence of population-based information. However, administrative databases that capture common health outcomes could serve to advance forest fire smoke epidemiology by allowing us to study smaller populations and to detect smaller effect estimates with the increased statistical power. Electronic registries of pharmaceutical dispensations provide such data, and have previously been used to evaluate the public health impacts of other short-lived events, such as human [15] and natural [16] disasters. Short-acting betaagonist (SABA) dispensations are specifically associated with acute exacerbations of obstructive lung diseases (such as asthma and chronic obstructive pulmonary disease), and they outnumber severe outcomes [17]. As such, SABA dispensations may be a more sensitive indicator of obstructive lung disease exacerbations within the population [18].

The Canadian province of British Columbia (BC) is regularly impacted by forest fires. It has both a comprehensive pharmaceutical database and a long-standing air quality monitoring network that covers many smaller communities. This setting provides a valuable opportunity to study the public health effects of forest fire smoke in smaller populations using a mild health outcome. Here we examine the associations between daily $\mathrm{PM}_{2.5}$ (PM less than 2.5 microns in diameter) and dispensations of medications used to relieve exacerbations of chronic respiratory diseases in fire-affected versus nonfire-affected populations between 2003 and 2010.

\section{Methods}

\section{Study area}

The study was conducted in the province of British Columbia (BC), on the west coast of Canada. Forest fires burn an average of $980 \mathrm{~km}^{2}$ per year in BC [19], and widespread infestation by the mountain pine beetle has left forests more susceptible to extreme events in recent years [20]. The province is geographically divided into 89 local health areas (LHAs), ranging in size from $40-130,000 \mathrm{~km}^{2}$ (Figure 1), and in 2006 population from 542 - 352,783 people [21]. Geographically smaller LHAs typically have larger populations living in urban and suburban areas, while larger LHAs have smaller populations living in rural and remote communities.

\section{Exposure assessment}

The air quality monitoring network in $\mathrm{BC}$ is maintained by the BC Ministry of Environment. Ambient concentrations of particulate matter (PM) are continuously measured at several stations by $\mathrm{PM}_{2.5}$ and/or $\mathrm{PM}_{10}$ (PM less than 10 microns in diameter) tapered element oscillating microbalances [22]. These instruments are heated to 30 or $40^{\circ} \mathrm{C}$ depending on their locations, and loss of volatile materials is expected to be less during the fires season than during the winter months [23]. We started by identifying all stations that had $\mathrm{PM}_{2.5}$ and/or $\mathrm{PM}_{10}$ measurements for every fire season (April 1 through September 30 ) in the study period. Any LHA with one or more of these stations was included in the study (Figure 1). For LHAs with multiple stations, the one closest to the LHA population center was used. As such, the daily PM exposure of the population within each study LHA was estimated using data from a single monitoring station within that LHA.

All PM data were converted to $\mathrm{PM}_{2.5}$ concentrations. For LHAs where $\mathrm{PM}_{2.5}$ measurements were available for the whole period, those data were used. For LHAs with some $\mathrm{PM}_{2.5}$ and some $\mathrm{PM}_{10}$ measurements, we adjusted $\mathrm{PM}_{10}$ to $\mathrm{PM}_{2.5}$ using the regression coefficients from linear models applied to all fire seasons when both instruments were running simultaneously. For LHAs with $\mathrm{PM}_{10}$ measurements only, or with insufficient overlap between instruments, we used the time-weighted average of linear regression coefficients from the other stations with simultaneous $\mathrm{PM}_{2.5}$ and $\mathrm{PM}_{10}$ measurements.

\section{Fire-affected LHAs and extreme fire days}

The air quality monitoring network measures PM contributions from all sources, including smoke from forest fires. We focused on the effects of fire smoke by using data from the Moderate Resolution Imaging Spectroradiometers (MODIS) to classify LHAs as fire-affected and non-fire-affected, and to identify extreme fire days,. These remote sensing instruments overpass most areas of the Earth four times daily, detecting fires at a resolution of $1 \mathrm{~km}^{2}$ at nadir [24]. The information recorded for each detected fire includes its central latitude and longitude, and a measure of its intensity, known as the fire radiative power (FRP, in MW). The FRP is proportional to aerosol emissions, and serves as a good indicator of the smoke generated by the detected fire [25-27]. We downloaded these data for $\mathrm{BC}$ and its surrounding areas from the Fire Information Resource Management System (FIRMS) [28], and used a geographic information system (GIS) to map all of the fires detected during the study period.

To assess the impact of fire on each LHA we used the GIS to draw a $100 \mathrm{~km}$ radius circle around its PM monitoring station, and then calculated the daily sum of FRP from all fires detected within that circle. Next, we aggregated daily FRP sums for all LHAs to examine the percentiles of the overall distribution. Finally, an LHA was defined as fire-affected if the plotted time-series of daily FRP values showed that the overall 95th percentile was exceeded in three or more of the nine fire seasons 


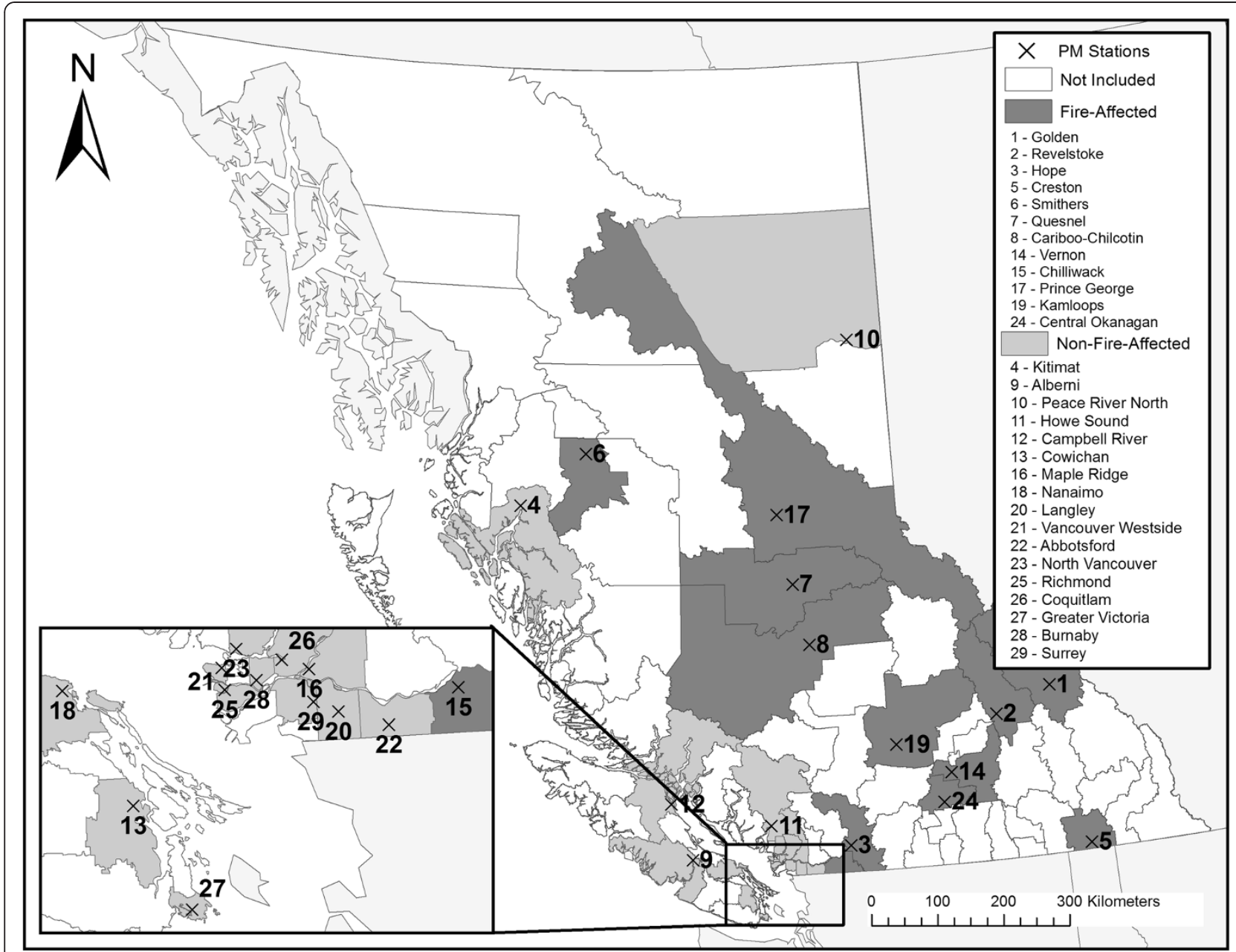

Figure 1 Map of the study region showing the local health areas (LHAs) included in the study, and the locations of the PM air quality monitoring stations. Study LHAs are numbered in order of increasing population, as in Table 1.

(Figure 2). To identify extreme fire days we summed all FRP values detected within and around $\mathrm{BC}$ for each day of the study period, and used the 80th, 90th, and 95th percentiles of the distribution to limit analyses to periods most likely affected by heavy smoke.

\section{Pharmaceutical dispensations}

Daily counts of pharmaceutical dispensations were received for each LHA from the BC PharmaNet database. Law requires that every prescription dispensed in the province be recorded in PharmaNet, regardless of the recipient or the payer [29]. We decided a priori to examine relationships between $\mathrm{PM}_{2.5}$ and counts for inhaled salbutamol sulfate, a selective beta-2-adrenoreceptor agonist that is commonly and specifically used to rapidly relieve exacerbations of asthma, COPD, and other obstructive lung diseases. Dispensations included all inhaled preparations of salbutamol available in BC (i.e. aerosol inhalers, powder inhalers and nebulizer solutions). Salbutamol preparations for ingestion were excluded. Other selective beta-2-adrenergic inhalants were also excluded, because preliminary analyses showed that they were rarely prescribed in BC (less than $5 \%$ of dispensations).

\section{Time-series models}

For every LHA included in the study we estimated the effect of daily $\mathrm{PM}_{2.5}$ concentrations on the rate of pharmaceutical dispensations for respiratory reliever medications, during all fire seasons and on extreme fire days. We used generalized linear models with natural cubic splines, adjusted for temperature, relative humidity, and temporal trends as shown in Equation 1.

$$
\begin{aligned}
& O_{t} \sim \operatorname{Poisson}\left(\mu_{t}, \sigma^{2}\right) \\
& \begin{aligned}
g\left(\mu_{t}\right)=P M_{l a g 01} & +n s\left(T_{t}, d f=3\right)+n s\left(R H_{t}, d f=3\right) \\
& +Y M D O W_{t}
\end{aligned}
\end{aligned}
$$



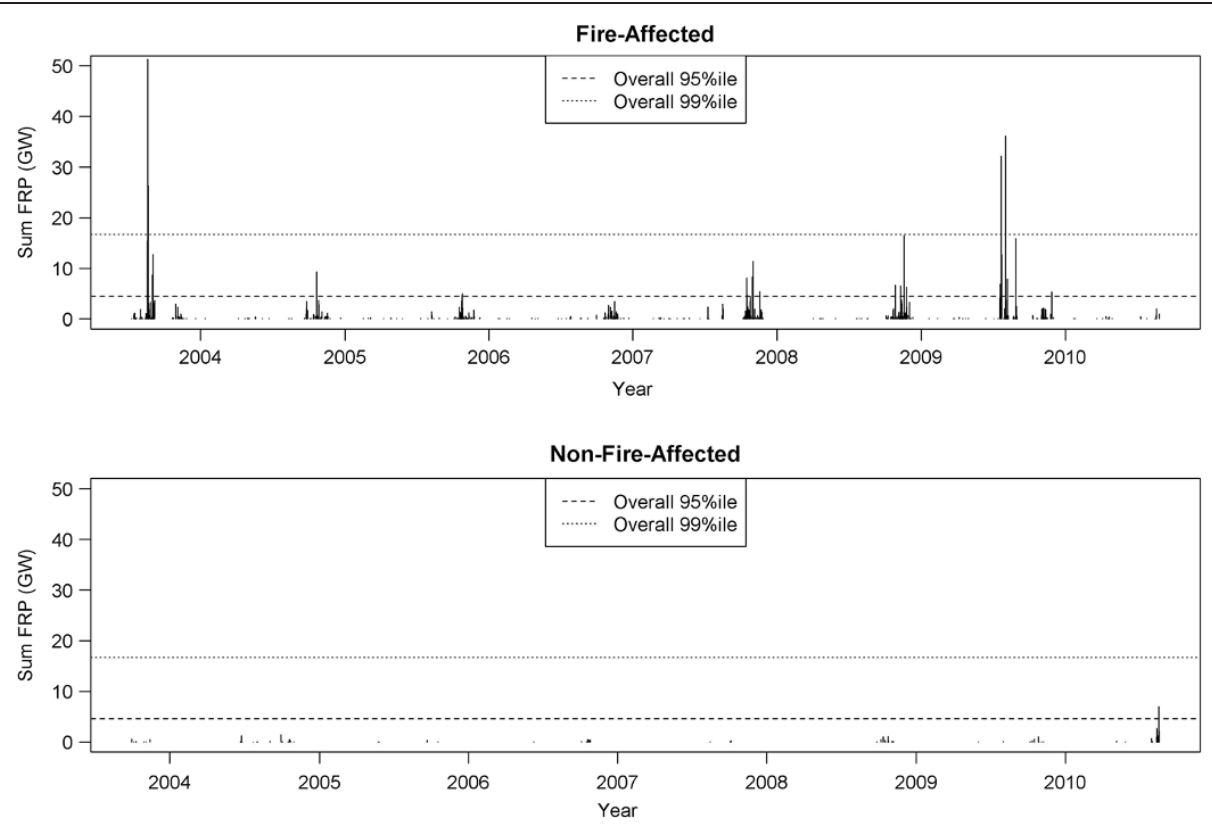

Figure 2 Examples of the time series of summed fire radiative power (FRP, in gigawatts) values for a fire-affected LHA (above, Central Okanagan) and a non-fire-affected LHA (below, Kitimat).

Where: $O_{t}=$ observed dispensation count in the LHA on day $t ; P M_{\text {lag01 }}=\mathrm{PM}_{2.5}$ concentration in the LHA averaged over days $t$ and $t-1 . ; T_{t}=$ mean temperature in the region of the LHA on day $t$, fitted as a natural cubic spline with three degrees of freedom; $R H_{t}=$ mean relative humidity in the region of the LHA on day $t$, fitted as a natural cubic spline with three degrees of freedom; $Y M D O W_{t}=$ year, month, and day of week (statutory holidays treated as Sundays) on day $t$, fitted as a factor variable with 378 levels (9 years * 6 months * 7 days). The resulting estimate of effect was the rate ratio (RR) associated with a $10 \mathrm{ug} / \mathrm{m}^{3}$ increase in $\mathrm{PM}_{2.5}$. A lag of 0-1 days was chosen for principal analyses based on model fit statistics from preliminary analyses, but lags of 0 through 7 days were tested. All analyses were completed in the R statistical computing environment [30]. After fitting individual models for each LHA, we conducted a random effects meta-regression using the inverse variance method [31] to estimate an overall effect for the fireaffected LHAs and the non-fire-affected LHAs during the fire season and on extreme fire days.

\section{Results}

\section{Included LHAs}

A total of 29 (out of 89) LHAs were included in the study (Table 1 and Figure 1). Their land areas ranged from 48 to $76,215 \mathrm{~km}^{2}$ and their 2006 populations ranged from 7,024 to 352,783 people. The average daily salbutamol dispensations ranged from 4.3 to 103.4 (Table 1). Most of the LHAs had $\mathrm{PM}_{2.5}$ measurements covering the majority of the study period, and $\mathrm{PM}_{10}$ concentrations were converted to $\mathrm{PM}_{2.5}$ with coefficients ranging from 0.27 to 0.69 , with an average of 0.49 . Mean fire season $\mathrm{PM}_{2.5}$ concentrations ranged from 2.8 to $11.8 \mathrm{ug} / \mathrm{m}^{3}$ across all stations. Maximum concentrations ranged from 33.4 to $248.1 \mathrm{ug} / \mathrm{m}^{3}$ for the 12 LHAs classified as fireaffected, and from 15.2 to $49.3 \mathrm{ug} / \mathrm{m}^{3}$ for the 17 LHAs that were not-fire-affected (Table 1). The mean $\mathrm{PM}_{2.5}$ concentrations on fire days in the 80th, 90th, and 95th percentiles of provincial FRP were 8.2, 9.6, and $11.2 \mathrm{ug} / \mathrm{m}^{3}$, respectively. In the 95th percentile there were 28 extreme fire days in 2003, 22 in 2009, 21 in 2010, 18 in 2004, 7 in 2006, 2 in 2007, and none in 2005 or 2008.

Associations between $\mathrm{PM}_{2.5}$ and salbutamol dispensations Fire season $\mathrm{PM}_{2.5}$ was positively associated with salbutamol dispensations in all fire-affected LHAs, with statistically significant results in 8 of 12 cases (Figure 3). The meta-regression RR (95\% confidence interval) for a $10 \mathrm{ug} / \mathrm{m}^{3}$ increase in $\mathrm{PM}_{2.5}$ was $1.06(1.04-1.07)$. The effect was evident at lags up to four days, decreasing to null by the fifth day. Fire season $\mathrm{PM}_{2.5}$ was not significantly associated with salbutamol dispensations in 15 of 17 non-fire-affected LHAs (Figure 4), with a metaregression RR $(95 \% \mathrm{CI})$ of $1.00(0.98-1.01)$. The two exceptions were a protective effect observed in Greater Victoria, and a positive association of $1.23(1.00-1.49)$ in Kitimat, where an aluminum smelter is an important source of PM and other air emissions. When analyses were restricted to fire days in the 80th, 90th, and 95th percentile of the provincial sum of FRP, the meta-regression RRs remained stable for the fire-affected LHAs (Figure 3), 
Table 1 Summary information for local health areas (LHAs) included in the analyses, listed in order of 2006 population

\begin{tabular}{|c|c|c|c|c|c|c|c|c|c|}
\hline LHA name & $\begin{array}{l}2006^{a} \\
\text { population }\end{array}$ & $\begin{array}{l}\text { Daily average } \\
\text { salbutamol } \\
\text { dispensations } \\
\text { (fire season) }\end{array}$ & $\begin{array}{l}\text { Area } \\
\left(\mathrm{km}^{2}\right)\end{array}$ & $\begin{array}{l}\text { Fire season } \\
\mathrm{PM}_{2.5}\end{array}$ & $\begin{array}{l}\text { Fire season } \\
\mathrm{PM}_{10}\end{array}$ & $\begin{array}{l}\mathrm{PM}_{2.5} / \mathrm{PM}_{10} \\
\text { coefficient }\end{array}$ & $\begin{array}{l}\text { Fire season } \\
\text { Mean } \mathrm{PM}_{2.5} \\
\left(\mu \mathrm{g} / \mathrm{m}^{3}\right)\end{array}$ & $\begin{array}{l}\text { Fire season } \\
\text { Max } \mathrm{PM}_{2.5} \\
\left(\mu \mathrm{g} / \mathrm{m}^{3}\right)\end{array}$ & $\begin{array}{l}\text { Fire- } \\
\text { affected? }\end{array}$ \\
\hline Golden & 7,024 & 4.5 & 13,350 & 2003-2010 & 2003-2010 & 0.51 & 5.7 & 74.0 & Y \\
\hline Revelstoke & 7,897 & 4.3 & 9,307 & $2007-2010$ & $2003-2007$ & $0.49^{b}$ & 7.1 & 81.7 & Y \\
\hline Hope & 8,062 & 4.9 & 5,280 & 2004-2010 & 2003-2010 & 0.48 & 5.0 & 33.4 & Y \\
\hline Kitimat & 10,443 & 5.1 & 19,639 & $2003-2010$ & $2003-2010$ & 0.44 & 2.8 & 24.8 & \\
\hline Creston & 11,917 & 6.8 & 3,789 & 2010 & $2003-2009$ & $0.49^{b}$ & 7.3 & 48.9 & Y \\
\hline Smithers & 16,073 & 7.1 & 9,827 & 2005-2010 & 2003-2010 & 0.27 & 4.2 & 66.8 & Y \\
\hline Quesnel & 22,930 & 11.7 & 23,732 & 2003-2010 & $2003-2010$ & 0.69 & 7.4 & 139.4 & Y \\
\hline Cariboo-Chilcotin & 26,150 & 12.9 & 44,695 & 2003-2010 & 2003-2010 & 0.59 & 6.1 & 248.1 & Y \\
\hline Alberni & 31,077 & 14.0 & 6,809 & - & $2003-2010$ & $0.49^{b}$ & 4.8 & 15.2 & \\
\hline Peace River North & 32,642 & 14.4 & 68,765 & - & $2003-2010$ & $0.49^{b}$ & 11.8 & 49.3 & \\
\hline Howe Sound & 32,327 & 12.6 & 9,236 & - & $2003-2010$ & $0.49^{b}$ & 8.3 & 33.7 & \\
\hline Campbell River & 40,173 & 18.0 & 13,624 & $2006-2010$ & 2003-2009 & 0.50 & 3.9 & 41.7 & \\
\hline Cowichan & 54,855 & 22.9 & 735 & 2010 & 2003-2009 & $0.49^{b}$ & 4.8 & 37.9 & \\
\hline Vernon & 62,227 & 29.9 & 5,555 & $2003-2010$ & $2003-2008$ & 0.38 & 5.4 & 130.8 & Y \\
\hline Chilliwack & 79,302 & 36.2 & 1,314 & 2003-2010 & $2003-2010$ & 0.40 & 5.3 & 35.7 & Y \\
\hline Maple Ridge & 88,020 & 32.3 & 1,450 & $2003-2010$ & $2003-2010$ & 0.45 & 5.5 & 36.5 & \\
\hline Prince George & 94,852 & 44.3 & 76,215 & $2003-2010$ & $2003-2010$ & 0.53 & 7.4 & 176.4 & Y \\
\hline Nanaimo & 98,561 & 46.5 & 1,289 & $2003-2010$ & - & - & 3.7 & 48.7 & \\
\hline Kamloops & 105,491 & 44.8 & 16,319 & $2003-2010$ & $2003-2008$ & 0.49 & 5.5 & 140.1 & Y \\
\hline Langley & 122,219 & 46.7 & 323 & 2003-2010 & 2003-2010 & 0.51 & 5.5 & 34.0 & \\
\hline Vancouver Westside & 129,011 & 24.6 & 48 & $2004-2010$ & $2003-2008$ & 0.52 & 5.5 & 32.1 & \\
\hline Abbotsford & 130,008 & 51.1 & 413 & 2010 & $2003-2010$ & $0.49^{b}$ & 6.9 & 23.9 & \\
\hline North Vancouver & 134,453 & 33.3 & 398 & - & $2003-2010$ & $0.49^{b}$ & 6.4 & 27.2 & \\
\hline Central Okanagan & 167,323 & 59.1 & 2,942 & $2003-2010$ & $2003-2008$ & 0.56 & 5.5 & 185.6 & Y \\
\hline Richmond & 182,652 & 37.5 & 124 & 2003-2010 & 2003-2010 & 0.51 & 5.0 & 40.3 & \\
\hline Coquitlam & 205,495 & 52.6 & 733 & $2004-2010$ & $2003-2008$ & 0.50 & 6.2 & 42.0 & \\
\hline Burnaby & 210,507 & 56.4 & 90 & 2003-2010 & $2003-2010$ & 0.45 & 5.2 & 42.7 & \\
\hline Greater Victoria & 217,374 & 65.4 & 113 & $2003-2010$ & - & - & 5.0 & 17.3 & \\
\hline Surrey & 352,783 & 103.4 & 333 & - & $2003-2010$ & $0.49^{b}$ & 7.1 & 19.1 & \\
\hline
\end{tabular}

The forest fire season is defined as April 1 - September 30 each year.

a 2006 was a national census year, and was also the midpoint of the study period.

${ }^{b}$ Average from all other stations used.

but increased with each restriction for the non-fireaffected LHAs (Figure 4). The point estimate was the same for both population types at the 95th percentile, with wider confidence intervals for the non-fire-affected group. The province-wide meta-regression estimate was 1.07 $(1.04-1.09)$ for the most extreme fire days.

\section{Discussion}

We found consistent associations between fire-related $\mathrm{PM}_{2.5}$ and salbutamol dispensations. During the fire season a $10 \mathrm{ug} / \mathrm{m}^{3}$ increase in $\mathrm{PM}_{2.5}$ was associated with a $6 \%$ increase in salbutamol dispensations $(R R=1.06$,
95\% CI 1.04-1.07) in fire-affected populations, but no effect was observed in non-fire-affected populations. On extreme fire days the same $\mathrm{PM}_{2.5}$ increase was associated with a 7\% increase in salbutamol dispensations in both types of populations (global RR $=1.07,95 \%$ CI 1.04-1.09). To the best of our knowledge there is only one other study of pharmaceutical dispensations and forest fires, which evaluated the aftermath of an extreme fire season in Galacia, Spain. Caamano-Isorna et al. [16] reported that male and female pensioners (age not specified) increased consumption of medications to relieve obstructive lung disease by $10.3 \%$ and $12.1 \%$, respectively, in the months 


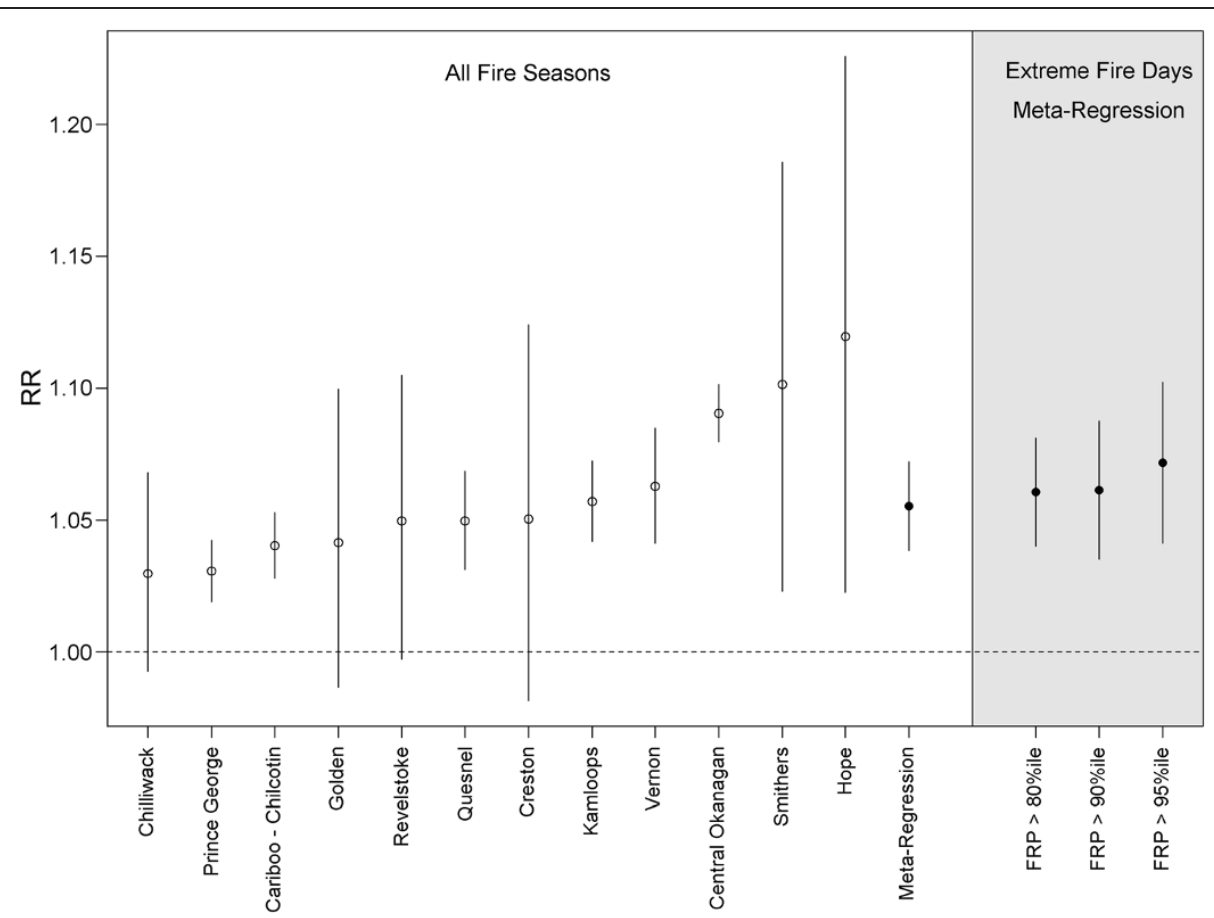

Figure 3 Regression results for the association between a $10 \mathrm{ug} / \mathrm{m}^{3}$ increase in $\mathrm{PM}_{2.5}$ (day-of and day-before average, lag ${ }_{01}$ ) and dispensation counts for the respiratory relief medication salbutamol sulfate in fire-affected local health areas (LHAs). Results for individual LHAs are ordered by the rate ratio (RR) point estimates for all fire seasons, followed by the meta-regression estimates for all fire seasons, and extreme fire days in the 80th, 90th, and 95th percentiles.

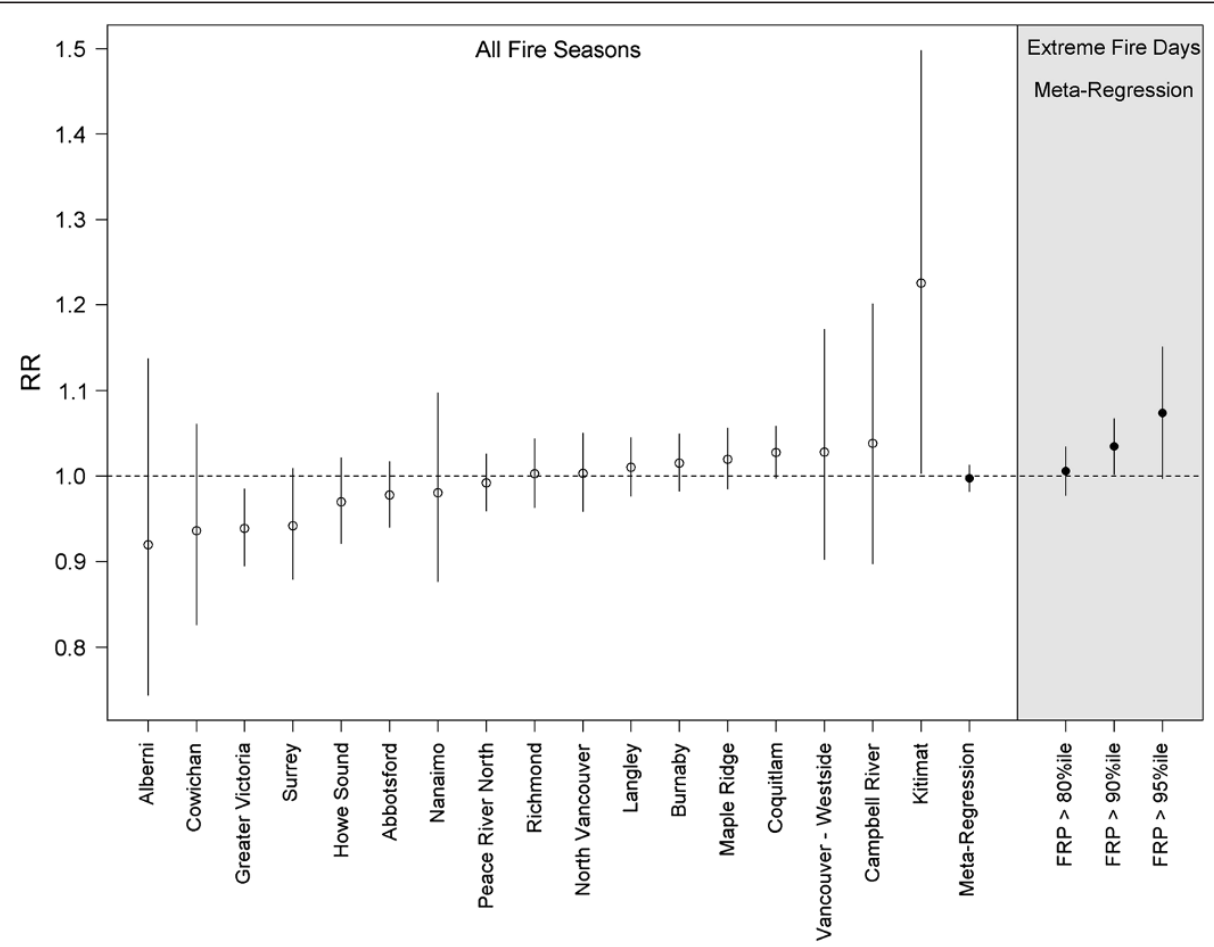

Figure 4 Regression results for the association between a $10 \mathrm{ug} / \mathrm{m}^{3}$ increase in $\mathrm{PM}_{2.5}$ (day-of and day-before average, lag ${ }_{01}$ ) and dispensation counts for the respiratory relief medication salbutamol sulfate in non-fire-affected local health areas (LHAs). Results for individual LHAs are ordered by the rate ratio (RR) point estimates for all fire seasons, followed by the meta-regression estimates for all fire seasons, and extreme fire days in the 80th, 90th, and 95th percentiles. 
following the severe fires, when compared with the previous months. No change was reported for non-pensioners.

Our results are consistent with other time-series studies on moderate to severe respiratory outcomes associated with exposure to forest fire smoke. Henderson et al. [9] reported that a $10 \mathrm{ug} / \mathrm{m}^{3}$ increase in $\mathrm{PM}_{10}$ was associated with a $6 \%$ increase in the odds of an asthmaspecific physician visit $(\mathrm{OR}=1.06,95 \%$ CI 1.03-1.08) during the 2003 fire season in BC. In the state of Victoria, Australia, Tham et al. (2009) [32] reported that a $10 \mathrm{ug} / \mathrm{m}^{3}$ increase in $\mathrm{PM}_{10}$ was associated with a $2 \%$ increase in the relative rate (RR) of all respiratory ED visits $(\mathrm{RR}=1.02,95 \%$ CI 1.00-1.03). In Los Angeles, California, Delfino et al. [7] reported that a $10 \mathrm{ug} / \mathrm{m}^{3}$ increase in $\mathrm{PM}_{2.5}$ was associated with a $3 \%$ increase in the rate of all respiratory hospital admissions $(\mathrm{RR}=1.03$, 95\% CI 1.01$1.04)$, a $5 \%$ increase in asthma admissions ( $R R=1.05,95 \%$ CI 1.02-1.08), and a $4 \%$ increase in chronic obstructive pulmonary disease admissions ( $\mathrm{RR}=1.04$, 95\% CI 1.001.08). Similarly, the Henderson et al. [9] study in BC also reported a $5 \%$ increase in the odds of all respiratory hospital admissions (OR $=1.05,95 \%$ CI 1.00-1.10). Finally, in Sydney, Australia, Johnston et al. [33] reported that extreme smoke events were associated with a $9 \%$ increase in the odds of respiratory mortality, though the estimate was not statistically significant $(\mathrm{OR}=1.09,95 \%$ CI 0.88-1.36).

Because ambient $\mathrm{PM}_{2.5}$ monitors cannot differentiate between PM sources, we used empirical remote sensing data to objectively classify populations as fire-affected or non-fire-affected, and to identify extreme fire days. While several other studies have used satellite-based methods to identify smoke-affected periods and areas $[1,7,9,34]$, our work is the first to leverage the fire radiative power measurements (proportional to smoke emissions) to classify populations and periods in this way. One might expect $\mathrm{PM}_{2.5}$ to have a clearer effect on salbutamol dispensations in LHAs where the smoke-related PM was extremely high, but this relationship was evident even in fire-affected LHAs with PM distributions that overlapped those of the non-fire-affected LHAs (Table 1). For example, the fire-affected LHA of Hope (population $=8,000$; peak $\mathrm{PM}_{2.5}=33.4 \mathrm{ug} / \mathrm{m}^{3}$; mean $\mathrm{PM}_{2.5}=5.0 \mathrm{ug} / \mathrm{m}^{3}$ ) had a significant association $(\mathrm{RR}=1.12,95 \% \mathrm{CI} 1.02-1.22)$, whereas the non-fire-affected LHA of Howe Sound (population $=32,000 ;$ peak $\mathrm{PM}_{2.5}=33.7 \mathrm{ug} / \mathrm{m} 3$, mean $\left.\mathrm{PM}_{2.5}=8.2\right)$ did not ( $\mathrm{RR}=0.97,95 \%$ CI 0.92-1.02). One outlier among the non-fire-affected LHAs was Kitimat $(\mathrm{RR}=1.23,95 \%$ CI 1.00-1.50), which is the site of an aluminum smelter. ${ }^{\text {a }}$ The population may therefore be exposed to $\mathrm{PM}_{2.5}$ that has a different toxicological profile than that in the other LHAs.

Fire smoke often affects small populations because forest fires most commonly burn in rural and remote areas; extreme events that affect large cities are relatively rare. However, it has been challenging to find associations between more severe respiratory outcomes and smoke exposure in smaller populations. During the 2003 fire season in BC, Moore et al. [35] detected an increase in weekly respiratory physician visits in one larger community (approximate population 185,000) with heavy smoke, but not in a smaller nearby community (approximate population 110,000) with more moderate smoke. In Darwin, Australia (approximate population 110,000) Johnston et al. [10,33] conducted two studies of respiratory

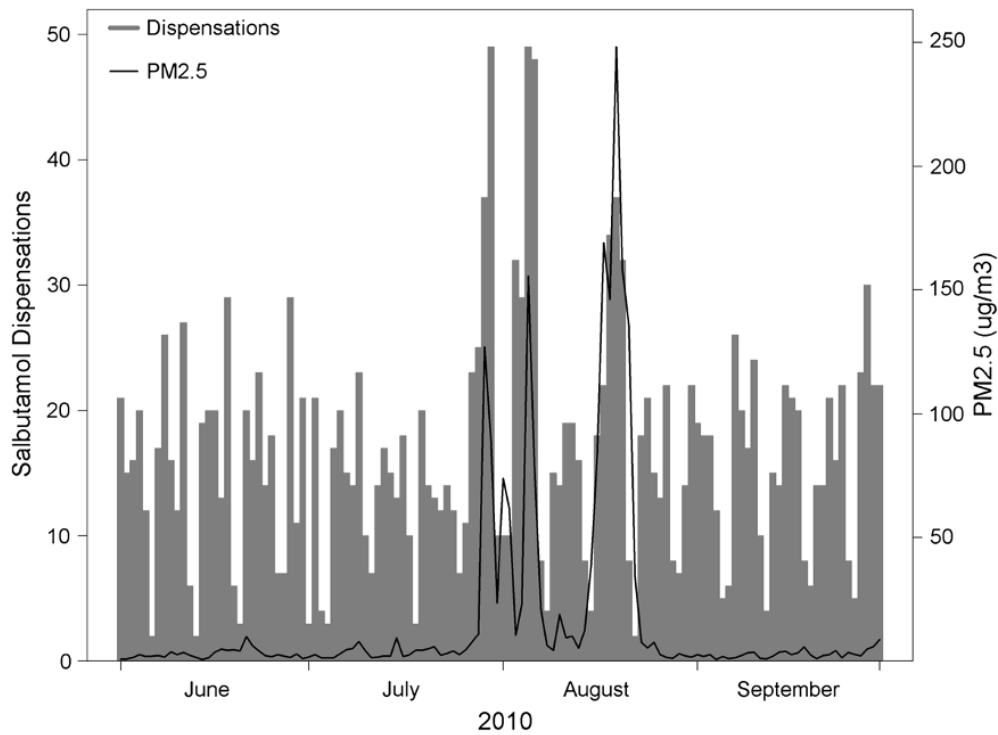

Figure 5 Daily time-series of salbutamol dispensations compared with $\mathrm{PM}_{2.5}$ concentrations in the Cariboo-Chilcotin LHA during the summer of 2010. Days with low counts are weekends and holidays, when many pharmacies are closed. 
outcomes associated with ambient $\mathrm{PM}_{10}$ during the forest fire season. The first was an ecological study that detected significant increases in daily asthma ED visits only when concentrations were over $40 \mathrm{ug} / \mathrm{m}^{3}$ [33]. The second was a case-crossover study on three years of hospital admissions [10]. Although the maximum daily concentration was $70 \mathrm{ug} / \mathrm{m}^{3}$, the positive associations were not statistically significant. In contrast, we have found strong and significant effects of $\mathrm{PM}_{2.5}$ on salbutamol dispensations in fire-affected populations ranging in size from 8,000 to 170,000 persons. Given that dispensations occur more frequently than severe outcomes, we suggest that they are more useful for studying the health effects of forest fire smoke in small populations. Furthermore, we observed that salbutamol dispensations rose rapidly in response to heavy smoke and fell rapidly as the smoke cleared (Figure 5), suggesting that dispensations may also be a responsive outcome for public health surveillance during smoke events.

There are important limitations to our analyses. First, this was an ecological study design, so we were unable to explore effect modification by individual factors. Second, a pharmaceutical dispensation does not necessarily reflect a disease exacerbation. Individuals with chronic lung disease may have sufficient reliever medication on hand, and not require a new dispensation for each exacerbation. Those who fill a prescription may do so for reasons related to the fire smoke (e.g., anticipated smoke effects), or for reasons that are completely unrelated (e.g., routine prescription renewal). Finally, we used data from single air quality monitoring stations to represent the exposure of populations within entire LHAs, some of which cover large geographic areas. Although most people in each LHA live in the monitored community, this homogenous approach to exposure assessment cannot account for the spatial variability inherent to fire smoke exposure.

Effective public health response to forest fire smoke events requires an understanding of its short-term health effects in order to identify who is most at risk, and to implement strategies to protect them. During milder events, the public health response may be limited to public education, but it should be rapidly escalated to provision of air shelters and/or evacuation as health risks increase. We have shown that pharmaceutical dispensations can be used to assess the population health effects in small communities. Given that these data are available in near-realtime, routine surveillance of pharmaceutical dispensations could play an important role in public health situational awareness and response. Further analyses are required to characterize short-term trends, and to create the indicators necessary to support fire smoke response guidelines.

\section{Conclusions}

We report a clear association between fire-related $\mathrm{PM}_{2.5}$ and salbutamol dispensations in $\mathrm{BC}$. The changes in salbutamol dispensations were observed in smaller populations than previously reported for any respiratory outcome (range: 8,000 to 170,000 persons, median: 26,000 ). This suggests that pharmaceutical dispensations can be leveraged in further research on acute respiratory events among small populations. Furthermore, this outcome was responsive to smoke-related $\mathrm{PM}_{2.5}$ concentrations, and may therefore be particularly useful for public health surveillance during forest fire smoke events.

\section{Endnotes}

${ }^{a}$ Note that the FRP time-series for Kitimat is the bottom panel of Figure 2, clearly showing little fire activity in the area.

\section{Abbreviations}

$\mathrm{PM}_{10}$ : PM less than 10 microns in diameter; $\mathrm{PM}_{2.5}$ : PM less than 2.5 microns in diameter; RR: Rate ratio; $\mathrm{Cl}$ : Confidence intervals; SABA: Short acting beta agonist; ED: Emergency department; BC: British Columbia; $\mathrm{km}^{2}$ : Square kilometers; LHAs: Local health authority; FPR: Fire radiative power; MW: Megawatts; GIS: Geographic information system; FIRMS: Information Resource Management System; df: Degrees of freedom; $\mathrm{O}_{t}$ : Observed dispensation count in the LHA on day $t ; P_{\text {lagor }}$ PM $M_{2.5}$ concentration in the LHA averaged over days $t$ (same day) and $t-1$ (previous day); $T_{t}$ : Mean temperature in the region of the LHA on day $t ; R H_{t}$ : Mean relative humidity in the region of the LHA on day $t ; Y_{M D O W}$ : Year, month, and day of week (statutory holidays treated as Sundays) on day $t$; OR: Odds ratio.

\section{Competing interests}

The authors declare that they have no competing interests.

\section{Authors' contributions}

CTE conceived of and helped design the study, critically reviewed the analysis and drafted the manuscript. SBH helped design the study, led the analysis, and helped draft the manuscript. WW assisted with data analysis and critically reviewed the manuscript. All authors read and approved the final manuscript.

Received: 21 August 2012 Accepted: 10 January 2013

Published: 28 January 2013

\section{References}

1. Johnston F, Hanigan I, Henderson S, Morgan G, Bowman D: Extreme air pollution events from bushfires and dust storms and their association with mortality in Sydney, Australia 1994-2007. Environ Res 2011, 111(6):811-816.

2. Sastry N: Forest fires, air pollution, and mortality in Southeast Asia. Demography 2002, 39(1):1-23.

3. Hanninen $\mathrm{OO}$, Salonen $\mathrm{RO}$, Koistinen $\mathrm{K}$, Lanki T, Barregard $\mathrm{L}$, Jantunen $\mathrm{M}$ : Population exposure to fine particles and estimated excess mortality in Finland from an East European wildfire episode. J Exposure Sci Environ Epidemiol 2009, 19(4):414-422.

4. Morgan TE, Davis DA, Iwata N, Tanner JA, Snyder D, Ning Z, Kam W, Hsu YT, Winkler JW, Chen J-C, et al: Glutamatergic neurons in rodent models respond to nanoscale particulate urban air pollutants In Vivo and In Vitro. Environ Health Perspect 2011, 119(7):1003-1009.

5. Vedal S, Dutton SJ: Wildfire air pollution and daily mortality in a large urban area. Environ Res 2006, 102(1):29-35.

6. Morgan G, Sheppeard V, Khalaj B, Ayyar A, Lincoln D, Jalaludin B, Beard J, Corbett $S$, Lumley T: Effects of bushfire smoke on daily mortality and hospital admissions in Sydney, Australia. Epidemiology 2010, 21(1):47-55.

7. Delfino RJ, Brummel S, Wu J, Stern H, Ostro B, Lipsett M, Winer A, Street DH, Zhang $L$, Tjoa $T$, et al: The relationship of respiratory and cardiovascular hospital admissions to the southern California wildfires of 2003. Occup Environ Med 2009, 66(3):189-197.

8. Hanigan IC, Johnston FH, Morgan GG: Vegetation fire smoke, indigenous status and cardio-respiratory hospital admissions in Darwin, Australia, 1996-2005: a time-series study. Environ Health 2008, 7:42-54. 
9. Henderson SB, Brauer M, Macnab YC, Kennedy SM: Three measures of forest fire smoke exposure and their associations with respiratory and cardiovascular health outcomes in a population-based cohort. Environ Heal Perspect 2011, 119(9):1266-1271.

10. Johnston FH, Bailie RS, Pilotto LS, Hanigan IC: Ambient biomass smoke and cardio-respiratory hospital admissions in Darwin, Australia. BMC Public Health 2007, 7:240-247.

11. Kunii O, Kanagawa S, Yajima I, Hisamatsu Y, Yamamura S, Amagai T, Ismail ITS: The 1997 haze disaster in Indonesia: Its air quality and health effects. Arch Environ Heal 2002, 57(1):16-22.

12. Kunzli N, Avol E, Wu J, Gauderman WJ, Rappaport E, Millstein J, Bennion J, McConnell R, Gilliland FD, Berhane K, et al: Health effects of the 2003 Southern California wildfires on children. Am J Respir Crit Care Med 2006, 174(11):1221-1228.

13. Mott JA, Meyer P, Mannino D, Redd SC, Smith EM, Gotway-Crawford C Chase E: Wildland forest fire smoke: health effects and intervention evaluation, Hoopa, California. West J Med 2002, 176(3):157-162.

14. Vora C, Renvall MJ, Chao P, Ferguson P, Ramsdell JW: San Diego wildfires and asthmatics. J Asthma 2011 2007, 48(1):75-78.

15. Dorn T, Yzermans CJ, van der Zee J: Prospective cohort study into postdisaster benzodiazepine use demonstrated only short-term increase. J Clin Epidemiol 2007, 60(8):795-802.

16. Caamano-Isorna F, Figueiras A, Sastre I, Montes-Martínez A, Taracido M, Piñeiro-Lamas M: Respiratory and mental health effects of wildfires: an ecological study in Galician municipalities (north-west Spain). Environ Heal 2011, 10(Suppl 1):48-56.

17. Naureckas ET, Dukic V, Bao X, Rathouz P: Short-acting beta-agonist prescription fills as a marker for asthma morbidity. Chest 2005, 128(2):602-608.

18. Menichini F, Mudu P: Drug consumption and air pollution: an overview. Pharmacoepidemiol Drug Safety 2010, 19(12):1300-1315.

19. Hanada A, Sander M, Gonzalez-Alonso J: Human skeletal muscle sympathetic nerve activity, heart rate and limb haemodynamics with reduced blood oxygenation and exercise. J Physiol 2003, 551(Pt 2):635-647.

20. Kurz WA, Dymond CC, Stinson G, Rampley GJ, Neilson ET, Carroll AL, Ebata T, Safranyik L: Mountain pine beetle and forest carbon feedback to climate change. Nature 2008, 452(7190):987-990.

21. Morse Cl, Pritchard LJ, Wust RC, Jones DA, Degens $\mathrm{H}$ : Carbon monoxide inhalation reduces skeletal muscle fatigue resistance. Acta Physiol (Oxf) 2008, 192(3):397-401.

22. Patashnick H, Rupprecht EG: Continuous PM-10 measurements using the tapered element oscillating microbalance. J Air Waste Manag Assoc 1991 41:1079-1083.

23. Allen $G$, Sioutas $C$, Koutrakis P, Reiss R, Lurmann FW, Roberts PT: Evaluation of the TEOM method for measurement of ambient particulate mass in urban areas. J Air Waste Manag Assoc 1997, 47(6):682-689.

24. Justice CO, Giglio L, Korontzi S, Owens J, Morisette JT, Roy D, Descloitres J, Alleaume S, Petitcolin F, Kaufman Y: The MODIS fire products. Remote Sens Environ 2002, 83(1-2):244-262.

25. Freeborn PH, Wooster MJ, Hao WM, Ryan CA, Nordgren BL, Baker SP, Ichoku $C$ : Relationships between energy release, fuel mass loss, and trace gas and aerosol emissions during laboratory biomass fires. $J$ Geophys Res 2008, 113(D1):D01301.

26. Ichoku C, Kaufman YJ: A method to derive smoke emission rates from MODIS fire radiative energy measurements. IEEE Trans Geosci Remote Sens 2005, 43(11):26-36.

27. Kaufman YJ, Ichoku C, Giglio L, Korontzi S, Chu DA, Hao WM, Li RR, Justice CO: Fire and smoke observed from the Earth Observing System MODIS instrument-products, validation, and operational use. Int J Remote Sens 2003, 24(8):1765-1781.

28. Resch H, Zawinka C, Weigert G, Schmetterer L, Garhofer G: Inhaled carbon monoxide increases retinal and choroidal blood flow in healthy humans. Invest Ophthalmol Vis Sci 2005, 46(11):4275-4280.

29. Morgan SG: Prescription drug expenditures and population demographics. Heal Serv Res 2006, 41(2):411-428.

30. Flannigan $M$, Amiro B, Logan K, Stocks B, Wotton B: Forest fires and climate change in the 21st century. Mitig Adapt Strat Global 2006, 11(4):847-859.

31. Current statistics. http://bcwildfire.ca/hprScripts/WildfireNews/Statistics.asp.
32. Tham R, Erbas B, Akram M, Dennekamp M, Abramson MJ: The impact of smoke on respiratory hospital outcomes during the 2002-2003 bushfire season, Victoria, Australia. Respirology 2009, 14(1):69-75.

33. Johnston F, Hanigan I, Henderson S, Morgan G, Portner T, Williamson G, Bowman D: Creating an integrated historical record of extreme particulate air pollution events in Australian cities from 1994 to 2007. J Air Waste Manage Assoc 2011, 61(4):390-398.

34. Rappold AG, Stone SL, Cascio WE, Neas LM, Kilaru VJ, Carraway MS, Szykman $J$, Ising A, Cleve WE, Meredith JT, et al: Peat bog wildfire smoke exposure in rural North Carolina is sssociated with cardio-pulmonary emergency department visits assessed through syndromic surveillance. Environ Health Perspect 2011, 119(10):1415-1420.

35. Moore D, Copes R, Fisk R, Joy R, Chan K, Brauer M: Population health effects of air quality changes due to forest fires in British Columbia in 2003: Estimates from physician-visit billing data. Can J Public Health 2006, 97(2):105-108

doi:10.1186/1476-069X-12-11

Cite this article as: Elliott et al:: Time series analysis of fine particulate matter and asthma reliever dispensations in populations affected by forest fires. Environmental Health 2013 12:11.

\section{Submit your next manuscript to BioMed Central and take full advantage of:}

- Convenient online submission

- Thorough peer review

- No space constraints or color figure charges

- Immediate publication on acceptance

- Inclusion in PubMed, CAS, Scopus and Google Scholar

- Research which is freely available for redistribution

Submit your manuscript at www.biomedcentral.com/submit
C) Biomed Central 